\title{
sciforum
}

Conference Proceedings Paper

\section{Simulations of Pollutant Diffusion under Different Meteorological Conditions}

\author{
Le Cao ${ }^{1, *}$, Zhijie Li ${ }^{1,2,3}$ and Mengmeng Gao ${ }^{1}$ \\ 1 Key Laboratory for Aerosol-Cloud-Precipitation of China Meteorological Administration, \\ Nanjing University of Information Science and Technology, Nanjing 210044, China; mmgao@nuist.edu.cn \\ (M.G.) \\ 2 State Key Laboratory of Atmospheric Boundary Layer Physics and Atmospheric Chemistry, Institute of \\ Atmospheric Physics, Chinese Academy of Sciences, Beijing 100029, China; lizhijie@mail.iap.ac.cn (Z.L.) \\ 3 College of Earth and Planetary Sciences, University of Chinese Academy of Sciences, Beijing 100049, China; \\ lizhijie@mail.iap.ac.cn (Z.L.) \\ * Correspondence: le.cao@nuist.edu.cn; Tel.: +86-025-5869-9771 (L.C.)
}

\begin{abstract}
The diffusion of pollutants in the atmospheric boundary layer (ABL) is affected by various meteorological conditions, such as radiation, wind speed, and turbulent mixing. In order to estimate the influence of different factors on diffusion, the finite difference method is used to solve the diffusion equation of pollutants. We first compared the obtained numerical solution with the theoretical solution to verify the correctness of the numerical model. Then, by comparing the temporal and spatial evolution characteristics of pollutants under different types of pollutant source distributions and different meteorological conditions, the diffusion of pollutants under different conditions can be obtained.
\end{abstract}

Keywords: Diffusion equation; Meteorological condition; Distribution types

\section{Introduction}

Pollutant emitted into the atmospheric boundary layer (ABL), high-concentration pollutant events within the ABL have negative influences on human life in many aspects. The value of pollutant concentration in local area is affected by two factors, the emission source ${ }^{[1]}$ and the meteorological conditions ${ }^{[1-3,7-9]}$. Within a certain time period, the releasing rate of pollutant from sources can be considered as constant. Therefore, meteorological conditions have become the decisive factor which significantly influence the air quality. The meteorological factors which can affect atmospheric diffusion mainly include: wind and turbulence, vertical distribution of temperature, radiation and cloud, and properties of the underlying surface ${ }^{[3]}$.

The numerical simulation of air quality began in the 1960s, and it has evolved to the third generation of air quality model[10-13]. However, the impact of multi-point sources emissions under different meteorological conditions on the local air quality is less studied. Different distribution of pollutant sources may have significant differences on the air quality in the surrounding areas. Therefore, the main contents of this paper are listed as follows: obtaining the theoretical solution of a one-dimensional diffusion equation and verifying the 1-D model; simulating the influence of different wind speeds on the concentration of pollutants under two-dimensional model. 


\section{Governing Equations and Methods}

There are two basic types of methods for theoretical solution of air pollution distribution: The Lagrange method and the Euler method. The Lagrange method is mostly limited to the diffusion problems under stationary and uniform assumptions, the Euler method does not have such limitations. Therefore, Euler method is now mostly used to estimate the turbulent diffusion. Unfortunately, a difficulty known as the closure problem leads this method to only approximate the governing equations ${ }^{[14-15]}$.

\subsection{Governing Equations}

In this paper, we use the Euler method to capture the diffusion of the pollutant released from the surface. By applying the material balance of the pollutants, the evolution of pollutant concentration can be expressed as

$$
\frac{\partial \mathrm{C}}{\partial \mathrm{t}}+\frac{\partial\left(\mathrm{u}_{\mathrm{j}} \mathrm{C}\right)}{\partial \mathrm{x}_{\mathrm{j}}}=\mathrm{D} \frac{\partial^{2} \mathrm{C}}{\partial \mathrm{x}_{\mathrm{j}}{ }^{2}}+\mathrm{R}+\mathrm{S} .
$$

In Eq. (1), $C$ denotes the pollutant concentration, $\mathrm{u}_{j}$ denotes the $j$ th component of the fluid velocity, $\mathrm{D}$ denotes the molecular diffusivity, which is related to temperature, $\mathrm{R}$ is the chemical reaction rate, and $\mathrm{S}$ is the sink and source of pollutant. Based on Reynolds averaging method, gradient transport theory (the K-theory) and some prerequisites, the diffusion equation is simplified to:

$$
\frac{\partial \overline{\mathrm{C}}}{\partial \mathrm{t}}=-\overline{\mathrm{u}} \frac{\partial \overline{\mathrm{C}}}{\partial \mathrm{x}}-\overline{\mathrm{v}} \frac{\partial \overline{\mathrm{C}}}{\partial \mathrm{y}}-\overline{\mathrm{w}} \frac{\partial \overline{\mathrm{C}}}{\partial \mathrm{z}}+\mathrm{K}_{\mathrm{x}} \frac{\partial^{2} \overline{\mathrm{C}}}{\partial \mathrm{x}^{2}}+\mathrm{K}_{\mathrm{y}} \frac{\partial^{2} \overline{\mathrm{C}}}{\partial \mathrm{y}^{2}}+\mathrm{K}_{\mathrm{z}} \frac{\partial^{2} \overline{\mathrm{C}}}{\partial \mathrm{z}^{2}}
$$

$\mathrm{K}$ is turbulent-transfer coefficient.

\subsection{Numerical Schemes}

In this study, we choose the finite difference method ${ }^{[-6]}$ to solve the diffusion equation. Taking the one-dimensional case as an example, the turbulent diffusion equation becomes

$$
\frac{\partial \overline{\mathrm{C}}}{\partial \mathrm{t}}=-\overline{\mathrm{u}} \frac{\partial \overline{\mathrm{C}}}{\partial \mathrm{x}}+\mathrm{K}_{\mathrm{x}} \frac{\partial^{2} \overline{\mathrm{C}}}{\partial \mathrm{x}^{2}}
$$

By approximating the partial differential equation (3) using differential schemes, we can get:

$$
\frac{c_{i}^{n+1}-c_{i}^{n}}{\Delta t}=-\bar{u} \frac{\bar{c}_{i}^{n}-\bar{c}_{i-1}^{n}}{\Delta x}+K_{x} \frac{c_{i-1}^{n+1}-2 c_{i}^{n+1}+c_{i+1}^{n+1}}{\Delta x^{2}} .
$$

Then, we can obtain the evolution of pollutant concentration at every grid node.

\section{Results and Discussions}

\subsection{Verification of the Model}

\subsubsection{Theoretical Solution}

If the one-dimensional turbulent diffusion equation under calm conditions satisfies certain assumptions and initial boundary conditions. Through the principle of variable separation and superposition, we obtain the solution of the turbulent diffusion equation in a one-dimensional bounded domain as:

$$
\mathrm{C}(\mathrm{x}, \mathrm{t})=\sum_{\mathrm{n}=1}^{\infty} \frac{2 \mathrm{Q}_{0}}{\mathrm{n} \pi}\left[\cos \frac{\mathrm{n} \pi \mathrm{x}_{1}}{\mathrm{~L}}-\cos \frac{\mathrm{n} \pi \mathrm{x}_{2}}{\mathrm{~L}}\right] \cdot \mathrm{e}^{-\mathrm{K}\left(\frac{\mathrm{n \pi}}{\mathrm{L}}\right)^{2} \mathrm{t}} \cdot \sin \frac{\mathrm{n} \pi \mathrm{x}}{\mathrm{L}},
$$

Taking $\mathrm{x}_{1}=495 \mathrm{~m}$ and $\mathrm{x}_{2}=505 \mathrm{~m}$ as the emission range of the pollutant, which is the same as the resolution of the numerical model. $\mathrm{K}=1000 \mathrm{~m}$ approximately represents the infinite series. We obtained the result of theoretical solution. 
The 3rd International Electronic Conference on Atmospheric Sciences (ECAS 2020), 16-30 November 2020;

Sciforum Electronic Conference Series, Vol. 3, 2020

\subsubsection{Numerical Solution}

Under the calm condition, the main meteorological factor that affects the diffusion of the pollutant concentration is the value of eddy diffusivity. In general, for a micro-scale area, the eddy diffusivity in the horizontal direction can be considered as a constant in a certain time and space range. In this case, the horizontal turbulent-transfer coefficient $\mathrm{K}=1.5 \mathrm{~m}^{2} / \mathrm{s}$ is substituted into differential equations. The computational methods of one-dimensional model are as follows:

- Time step size: $\Delta \mathrm{t}=12 \mathrm{~s}$.

- Space resolution: $\Delta \mathrm{x}=10 \mathrm{~m}$.

- Initial conditions: the source emits pollutant with an initial concentration of $=300 \mathrm{ml} / \mathrm{m} 3$ at time $\mathrm{t}=0$.

- Boundary conditions: $\mathrm{c}=0$ at $\mathrm{x}=0 \mathrm{~m}$ and $\mathrm{x}=1000 \mathrm{~m}$.

Then, the spatial and temporal distribution of the gaseous pollutant concentration can be obtained.

Table 1 shows the comparison between the numerical results and the theoretical solution. From the table, we can see that the theoretical solution of the diffusion equation is nearly identical to that of the numerical model simulation, with an error less than 0.20 . Thus, the solution of the onedimensional numerical model is verified.

Table 1. Comparison between the numerical model and the theoretical model

\begin{tabular}{ccccccc}
\hline $\begin{array}{c}\text { Concentration } \\
\left(\mathbf{m} \mathbf{m} / \mathbf{m}^{\mathbf{3}}\right)\end{array}$ & $\mathbf{t}=\mathbf{0}$ & $\mathbf{t}=\mathbf{1 h}$ & $\mathbf{t}=\mathbf{2 h}$ & $\mathbf{t}=\mathbf{3 h}$ & $\mathbf{t}=\mathbf{4 h}$ & $\mathbf{t}=\mathbf{5 h}$ \\
\hline $\begin{array}{c}\text { Numerical } \\
\text { Model }\end{array}$ & 300 & 14.15 & 9.99 & 8.15 & 7.06 & 6.31 \\
$\begin{array}{c}\text { Theoretical } \\
\text { Model }\end{array}$ & 300 & 14.15 & 9.97 & 8.15 & 7.05 & 6.31 \\
\hline
\end{tabular}

\subsection{Two-Dimensional Diffusion Simulation}

In this section, we focus on the two types of three-point source distribution on the range of the pollution diffusion and concentration under different meteorological conditions. The first case is that the three point sources are in an isosceles right triangle shape; the second one is the three point sources are linearly distributed.

Based on some assumptions, Eq.(5) is converted into the differential format:

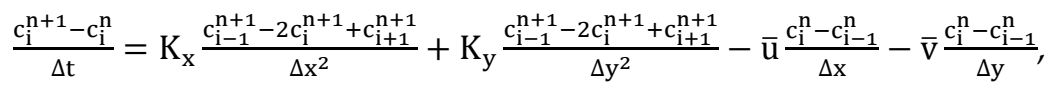

$\mathrm{K}_{\mathrm{x}}=\mathrm{K}_{\mathrm{y}}=1.0 \mathrm{~m}^{2} / \mathrm{s}$.

\subsubsection{Right Triangle Distribution}

Figs.1-3 show the change of pollutant concentration with time under different wind speed when the three point sources are located at $(300 \mathrm{~m}, 300 \mathrm{~m}),(300 \mathrm{~m}, 400 \mathrm{~m}),(400 \mathrm{~m}, 400 \mathrm{~m})$.

In the absence of wind (Fig.1), three dispersed plumes mixed with each other after 20 minutes of diffusion, the maximum concentration of pollutants decreases to $2.65 \mathrm{ml} / \mathrm{m}^{3}$; At time $\mathrm{t}=30 \mathrm{~min}$, the maximum concentration of pollutants decreases to $2.23 \mathrm{ml} / \mathrm{m}^{3}$ and all of the pollutant remains inside the simulated domain. Under the condition of no wind, the longer the diffusion distance of polluted air parcels, the easier it is affected by the surrounding point sources. Thus, we can see a continuous concentration distribution of gaseous pollutants and the slowing down of the reduction rate of concentration.

When the wind speeds along $x$ and $y$ direction increase to $1 \mathrm{~m} / \mathrm{s}$ (Fig.2), the three smoke plumes have been mixed with each other after five minutes, and the maximum concentration of pollutants is 
reduced to $2.32 \mathrm{ml} / \mathrm{m}^{3}$. At the 20th minute, most of the pollutants have diffused out of the simulation area. The maximum pollutant concentration has reduced to $0.68 \mathrm{ml} / \mathrm{m}^{3}$, which is $1.97 \mathrm{ml} / \mathrm{m}^{3}$ lower than that under windless condition at the same time. When the wind speed of each direction increase to $3 \mathrm{~m} / \mathrm{s}$ (Fig.3), the transport speed of pollutants is significantly accelerated. When time reaches 100 $\mathrm{s}$, different plumes have been mixed with each other, and the maximum

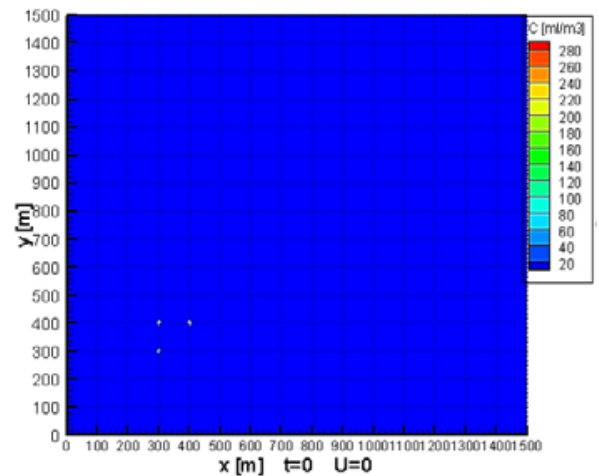

(a)

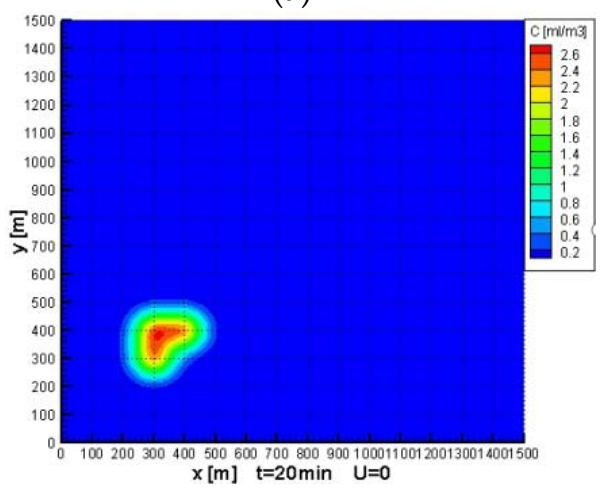

(c)

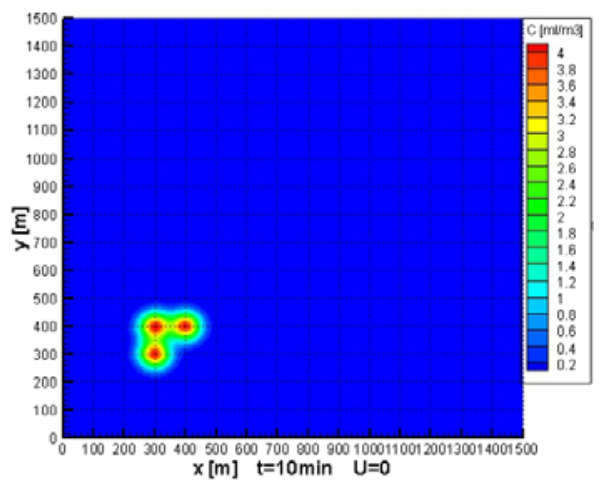

(b)

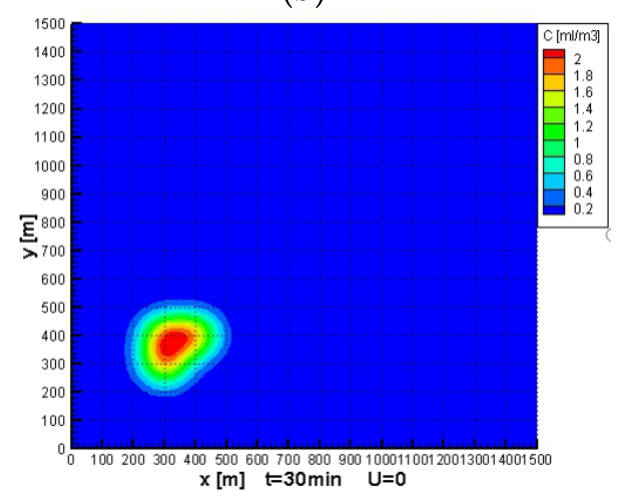

(d)

Figure 1. Right triangle distribution of sources under windless condition. (a) $t=0 ;(b) t=10 \min ;$ (c) $t$ $=20 \mathrm{~min} ;(\mathbf{d}) \mathrm{t}=30 \mathrm{~min}$.

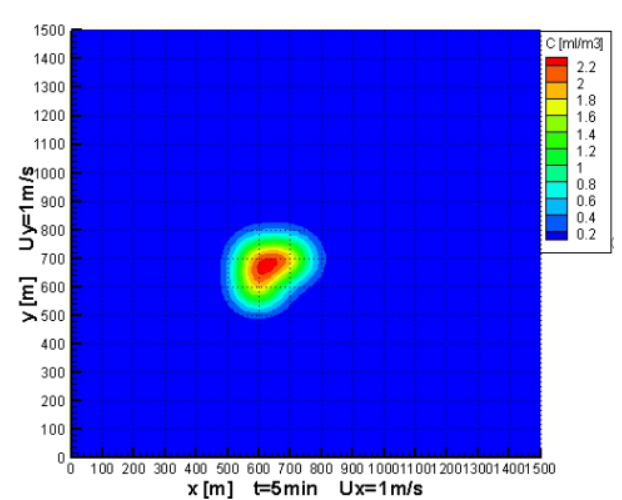

(a)

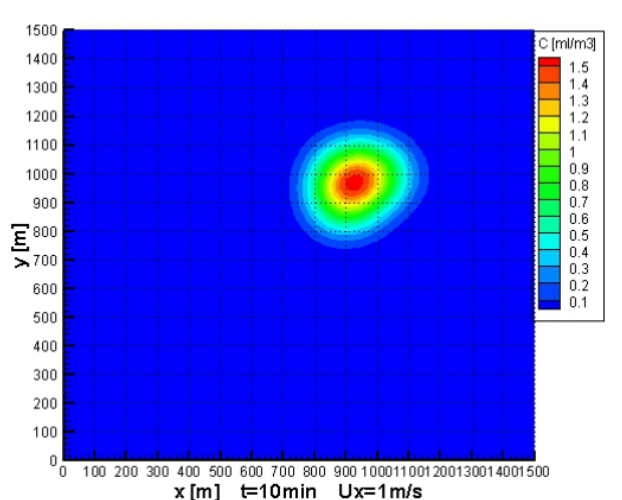

(b) 
The 3rd International Electronic Conference on Atmospheric Sciences (ECAS 2020), 16-30 November 2020;

Sciforum Electronic Conference Series, Vol. 3, 2020

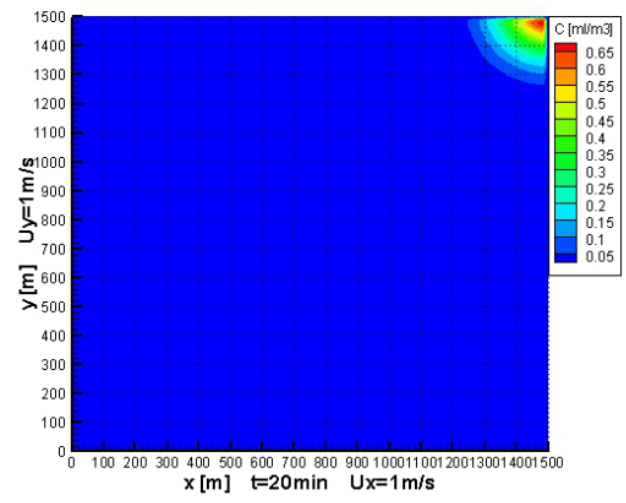

(c)

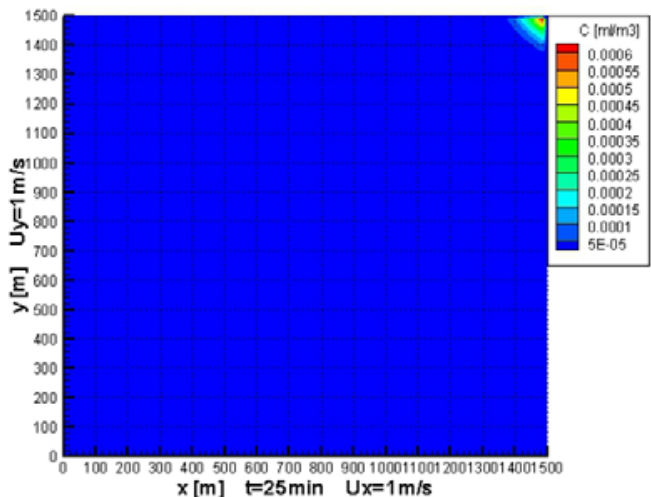

(d)

Figure 2. Right triangle distribution of sources when $u_{x}=u_{y}=1 \mathrm{~m} / \mathrm{s}$. (a) $t=5 \mathrm{~min} ;(\mathbf{b}) \mathrm{t}=10 \mathrm{~min} ;(\mathbf{c}) \mathrm{t}=$ $20 \mathrm{~min} ;(\mathbf{d}) \mathrm{t}=25 \mathrm{~min}$.

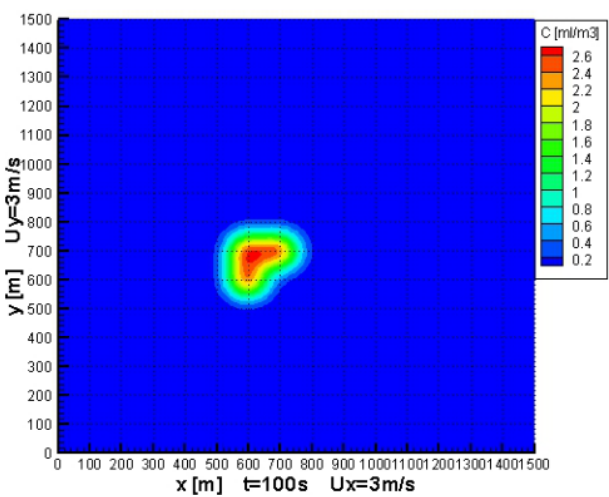

(a)

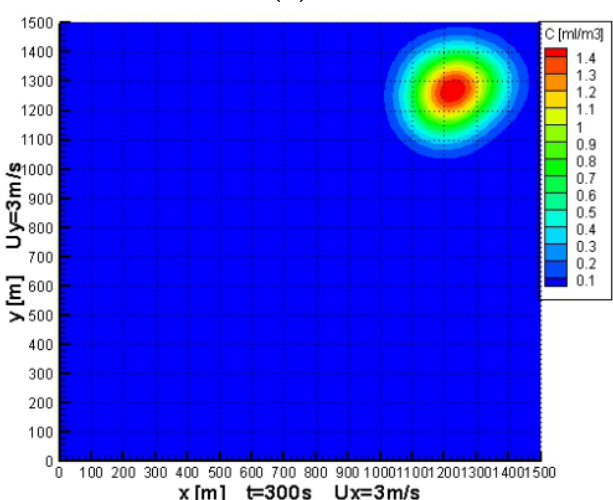

(c)

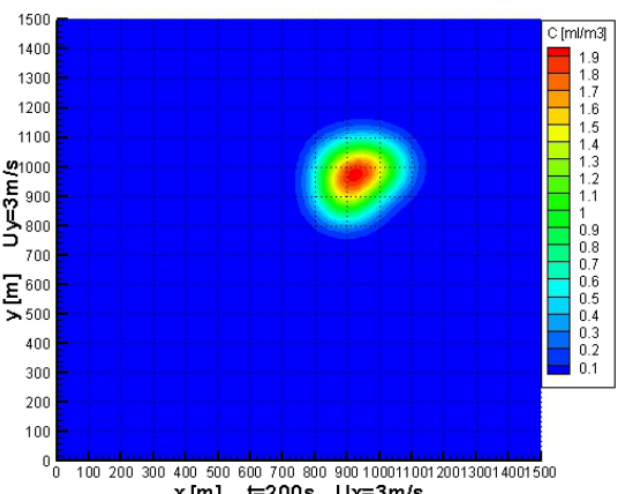

(b)

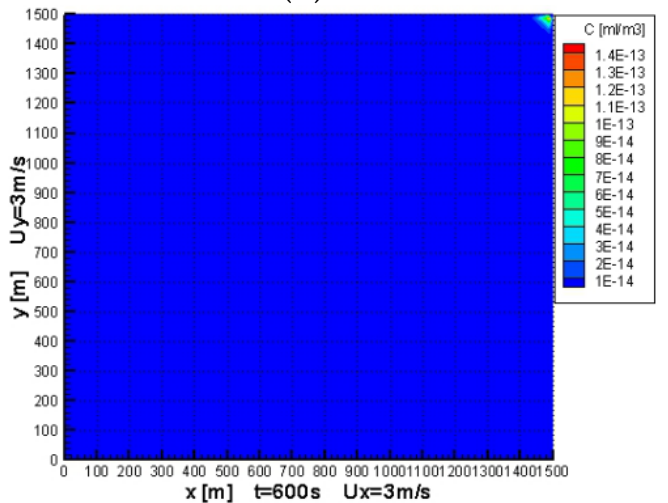

(d)

Figure 3. Right triangle distribution of sources when $u_{x}=u_{y}=3 \mathrm{~m} / \mathrm{s}$. (a) $t=100 \mathrm{~s} ;(\mathbf{b}) t=200 \mathrm{~s}$; (c) $t=$ $300 \mathrm{~s} ;(\mathbf{d}) \mathrm{t}=600 \mathrm{~s}$.

concentration of pollutants has decreased to $2.70 \mathrm{ml} / \mathrm{m}^{3}$; At the time $\mathrm{t}=10 \mathrm{~min}$, the maximum concentration of pollutants in the computational domain has decreased to an order of $\mathrm{ml} / \mathrm{m}^{3}$.

From the figures, we can see that, wind speed plays an important role in the transport and diffusion of pollutants. This is because more ambient air is mixed into the smoke plumes with an increasing wind speed, leading a lower concentration of pollutant.

\subsubsection{Linear Distribution}


Figs.4-6 show the distribution of pollutant concentrations under different wind speeds when the three point sources are located at $(200 \mathrm{~m}, 400 \mathrm{~m}),(300 \mathrm{~m}, 300 \mathrm{~m}),(400 \mathrm{~m}, 200 \mathrm{~m})$. The information that can be seen directly from the picture, we will not repeat it.

Tables 2 and 3 show the relationship between the maximum concentration of pollutants and the time of different distribution types when there is no wind and $u x=u x=1 \mathrm{~m} / \mathrm{s}$. By Comparing these two different simulation types, we can see:

Under windless conditions, the maximum value of pollutant concentration simulated in type 1 is higher than type 2 at the same time. The deficits at $\mathrm{t}=10 \mathrm{~min}, \mathrm{t}=20 \mathrm{~min}, \mathrm{t}=30 \mathrm{~min}$ of the two types are $0.14 \mathrm{ml} / \mathrm{m}^{3}, 0.58 \mathrm{ml} / \mathrm{m}^{3}$, and $0.73 \mathrm{ml} / \mathrm{m}^{3}$, respectively. This is due to the fact that the distribution of type 1 is more closely distributed than that of type 2. Plumes closer in distance can mix with each other in a shorter time, resulting in a superposition of concentration.

When the horizontal component of wind speed is $1 \mathrm{~m} / \mathrm{s}$. Due to the transport of wind, the amount of air mixed per unit volume increases compared with windless conditions, and the concentration of pollutants at the same time is significantly reduced. 10 minutes after the releasing of smoke, the pollutant peak concentration of type 2 is obviously lower than that of type 1 , which shows that the sparsely distributed method was more conducive to the reduction of pollutant concentration. When the diffusion time reaches the 20th minute, the difference in concentration of these two types is not so obvious.

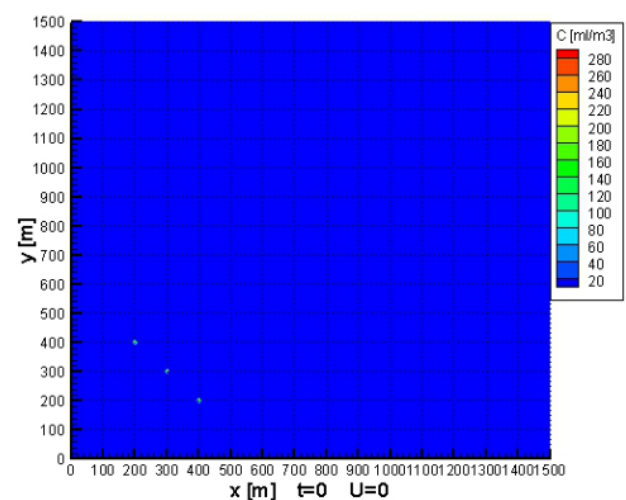

(a)

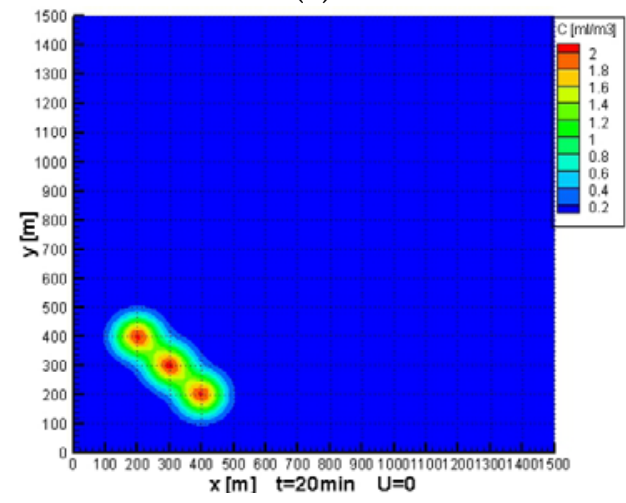

(c)

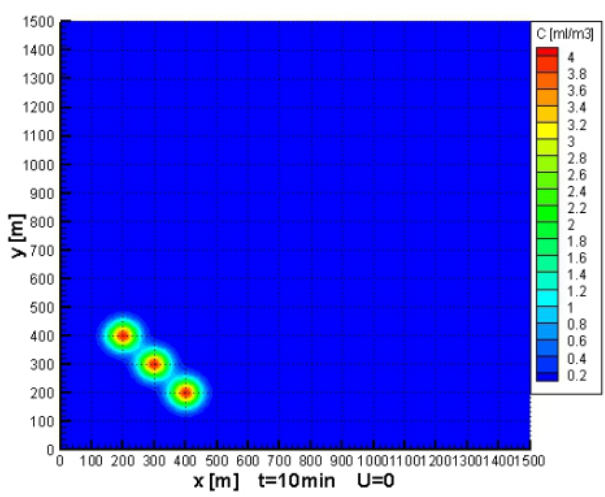

(b)

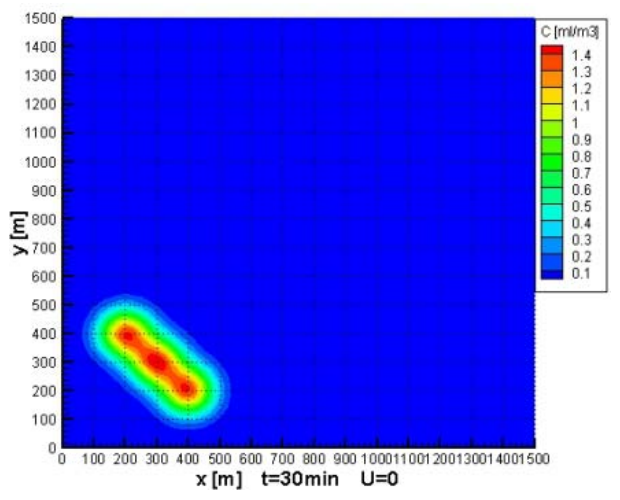

(d)

Figure 4. Diffusion of linear distribution under windless condition. (a) $t=0 ;(b) t=10$ min; (c) $t=20$ $\min ;(d) t=30 \mathrm{~min}$. 
The 3rd International Electronic Conference on Atmospheric Sciences (ECAS 2020), 16-30 November 2020; Sciforum Electronic Conference Series, Vol. 3, 2020

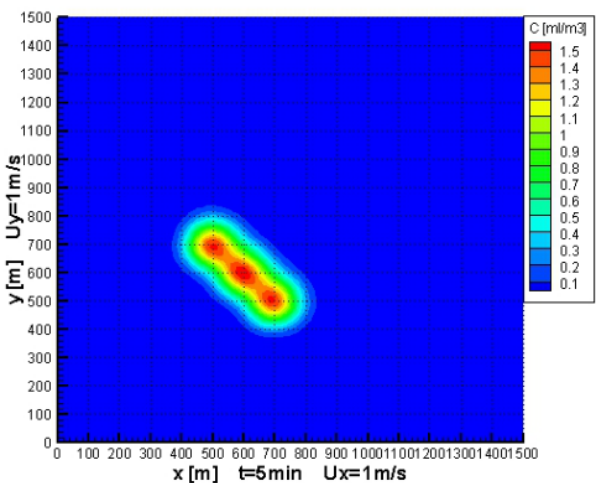

(a)

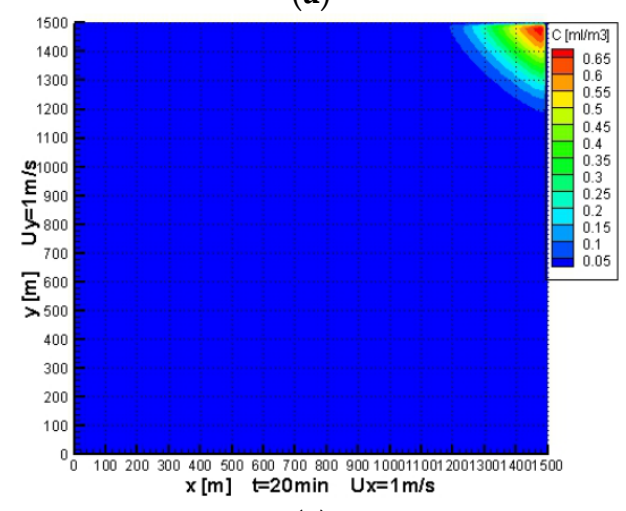

(c)

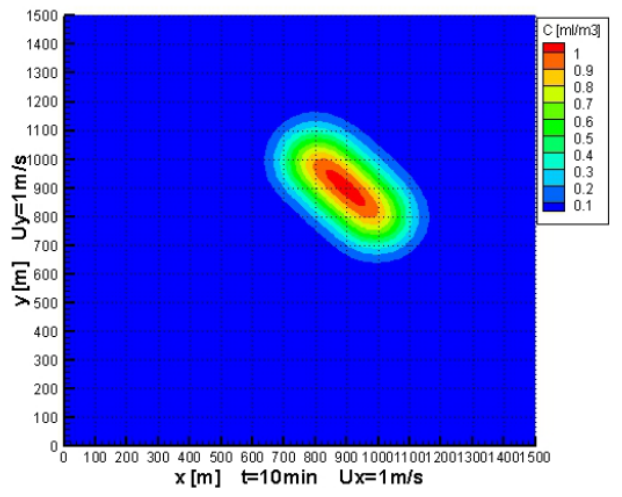

(b)

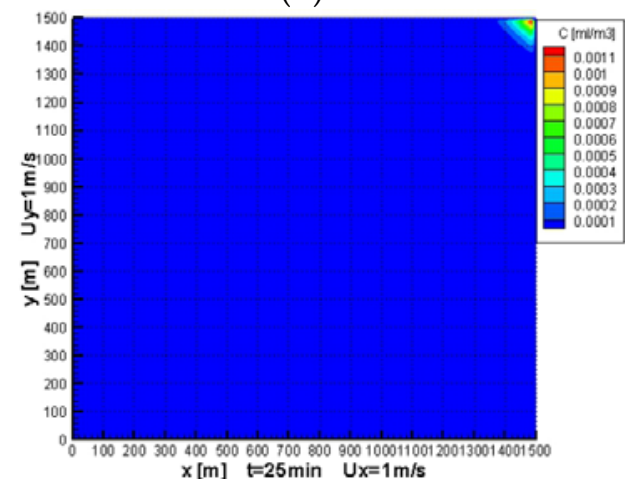

(d)

Figure 5. Distribution of linear distribution when $u_{x}=u_{y}=1 \mathrm{~m} / \mathrm{s}$. (a) $t=5 \mathrm{~min} ;(\mathbf{b}) t=10 \mathrm{~min} ;(\mathbf{c}) t=20$ $\min ;(d) t=25 \min$.

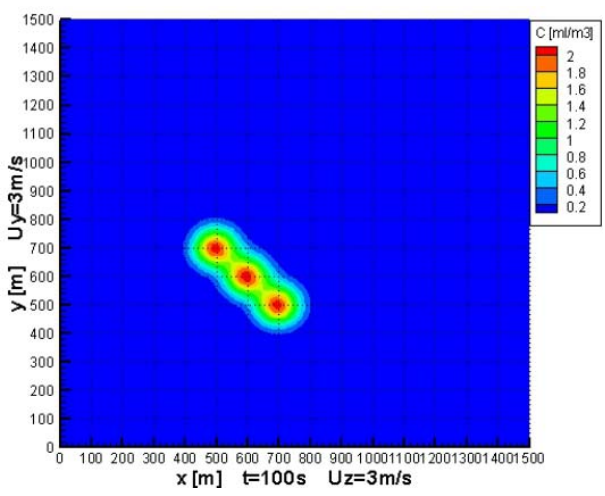

(a)

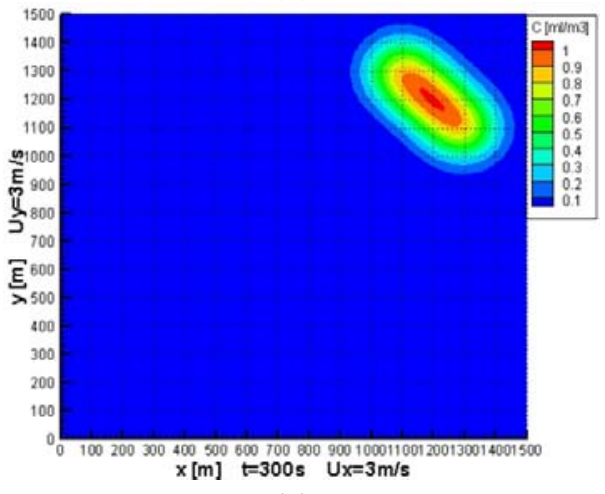

(c)

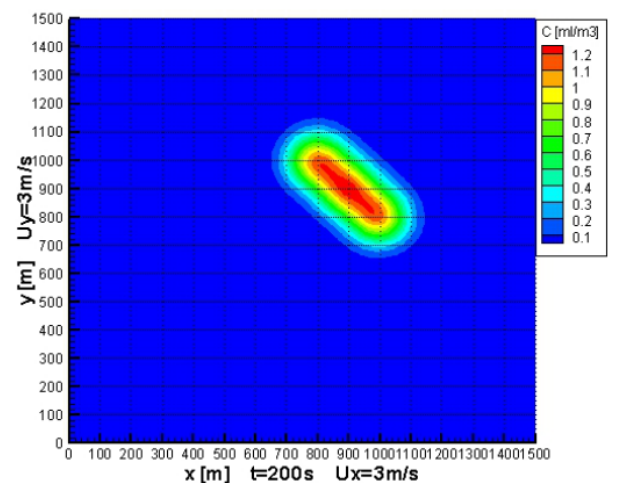

(b)

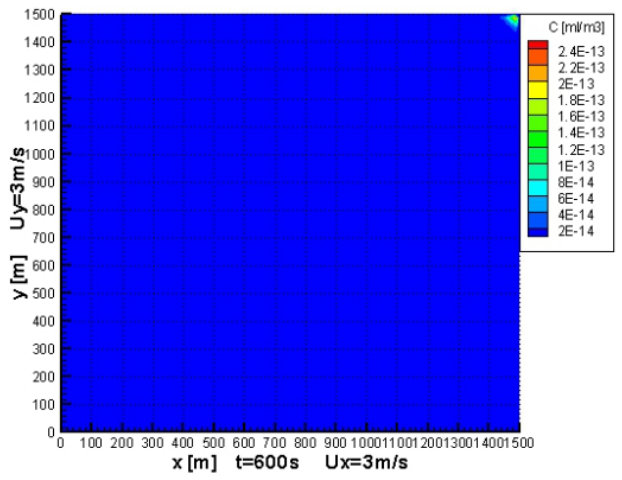

(d)

Figure 6. Distribution of linear distribution when $u_{x}=u_{y}=3 \mathrm{~m} / \mathrm{s}$. (a) $t=100 \mathrm{~s} ;(\mathbf{b}) \mathrm{t}=200 \mathrm{~s} ;(\mathbf{c}) \mathrm{t}=300 \mathrm{~s}$; (d) $\mathrm{t}=600 \mathrm{~s}$. 
The 3rd International Electronic Conference on Atmospheric Sciences (ECAS 2020), 16-30 November 2020; Sciforum Electronic Conference Series, Vol. 3, 2020

When the wind speed along each direction both increase to $3 \mathrm{~m} / \mathrm{s}$. The pollutant concentration of the two schemes is reduced to a level of $10^{-13} \mathrm{ml} / \mathrm{m}^{3}$ within 10 minutes. It shows that the increase of wind speed has a significant effect on the transport and diffusion of smoke. Under the condition of a larger wind speed, pollutants emitted by pollution sources can be transported and diluted in a very short time.

Table 2. Comparison between two types under windless condition

\begin{tabular}{cccc}
\hline $\begin{array}{c}\text { Concentration } \\
\left(\mathbf{m l} / \mathbf{m}^{\mathbf{3}}\right)\end{array}$ & $\mathbf{t} \mathbf{=} \mathbf{1 0} \mathbf{~} \mathbf{m i n}$ & $\mathbf{t}=\mathbf{2 0} \mathbf{~} \mathbf{m i n}$ & $\mathbf{t}=\mathbf{3 0} \mathbf{~ m i n}$ \\
\hline Type 1 & 4.21 & 2.65 & 2.23 \\
Type 2 & 4.07 & 2.07 & 1.50 \\
Difference & 0.14 & 0.58 & 0.73 \\
\hline
\end{tabular}

Table 3. Comparison between the two schemes when $\mathrm{ux}_{\mathrm{x}}=\mathrm{u}_{\mathrm{y}}=1 \mathrm{~m} / \mathrm{s}$.

\begin{tabular}{ccccc}
\hline $\begin{array}{c}\text { Concentration } \\
\left(\mathbf{m l} / \mathbf{m}^{\mathbf{3}}\right)\end{array}$ & $\mathbf{t}=\mathbf{5} \mathbf{~} \mathbf{m i n}$ & $\mathbf{t}=\mathbf{1 0} \mathbf{~} \min$ & $\mathbf{t}=\mathbf{2 0} \mathbf{~} \operatorname{in}$ & $\mathbf{t}=\mathbf{2 5} \mathbf{~} \mathbf{i n}$ \\
\hline Type 1 & 2.32 & 1.56 & 0.68 & $6.4 \times 10^{-4}$ \\
Type 2 & 1.58 & 1.04 & 0.67 & $1.2 \times 10^{-3}$ \\
Difference & 0.74 & 0.52 & 0.01 & $-5.6 \times 10^{-4}$ \\
\hline
\end{tabular}

\section{Conclusions}

In this paper, we mainly discuss the content in two aspects, the theoretical verification of onedimensional numerical model, the diffusion of pollutants under different meteorological conditions for different distribution schemes. The specific conclusions are as follows:

- Comparing the theoretical and numerical solutions under one-dimensional conditions, it is found that the difference between the two can be ignored, which proves that the finite difference method is correct to solve the one-dimensional turbulence equation.

- The wind speed contributes significantly to the dilution of pollutants; more air is mixed into the smoke plumes under windy conditions within the same time period compared with windless condition.

- Wind speed plays an important role in the transport of pollutant. When there is no wind, all the pollutants are still in the simulation area after 30 minutes of diffusion. Under windy conditions, pollutants can move out of the simulation area in a short time.

- When there are three pollutant sources, because the right-angled distribution is more tightly arranged than the linearly-distributed sources, smoke plumes interact with each other more easily, resulting in the superposition of pollutant, and thus forming a high concentration of pollution in a short time in local area.

Acknowledgments: This work is financially supported by the National Natural Science Foundation of China (No. 41375044). The numerical calculations in this paper have been done on the high performance computing system in the High Performance Computing Center, Nanjing University of Information Science \& Technology.

\section{References}

1. Blanchard, C L.; Roth, P M. Use of ambient data to corroborate analyses of ozone control strategies[J]. Atmospheric Environment, 1999, 3(33): 369-381.

2. He J; Gong S. Air pollution characteristics and their relation to meteorological conditions during 2014-2015 in major Chinese cities[J]. Environmental Pollution, 2017, (223): 484-496.

3. Stull R B. An introduction to boundary layer meteorology[M]. U.S.A: Kluwer Academic Publishers. 2003:317. 
The 3rd International Electronic Conference on Atmospheric Sciences (ECAS 2020), 16-30 November 2020;

Sciforum Electronic Conference Series, Vol. 3, 2020

4. Author 1, A.B. (University, City, State, Country); Author 2, C. (Institute, City, State, Country). Personal communication, 2012.

5. Sun Z Z, Wu X N. A Fully Discrete Difference Scheme for a Diffusion-Wave System[J]. Applied Numerical Mathematics, 2006, 56(2): 193-209.

6. Shen S, Liu F. Numerical approximations and solution techniques for the space-time Riesz-Caputo fractional advection-diffusion equation[J]. Numerical Algorithms, 2011, 56(3): 383-403.

7. Blanchard C L, Stoeckenius T. Ozone response to precursor controls: comparison of data analysis methods with the predictions of photochemical air quality simulation models[J]. Atmospheric Environment, 2001, 7(35): 1203-1215.

8. Blanchard, Charles L. Use of ambient data to corroborate analyses of ozone control strategies[J]. Atmospheric Environment, 1999, 3(33): 369-381.

9. Liu Y W, Xie S J. Short-term effects of ambient air pollution on pediatric outpatient visits for respiratory diseases in Yichang city, China[J]. Environmental Pollution, 2017, (227): 116-124.

10. Silverman K C, Tell J G. Comparison of the Industrial Source Complex and AERMOD Dispersion Models: Case Study for Human Health Risk Assessment[J]. Air \& Waste Management Association, 2007, 57(12): 1439-1446.

11. Gery M W, Whitten G Z. A photochemical kinetics mechanism for urban and regional scale computer modeling[J]. Journal of Geophysical Research Atmospheres, 1989, 94 (D10): 12925-12956.

12. Chu K J, Seinfeld J H. Formulation and initial application of a dynamic model for urban aerosols[J]. Atmospheric Environment, 1975, 4(9): 375-402.

13. Stockwell W R, Middleton P. The second generation regional acid deposition model chemical mechanism for regional air quality modeling[J]. Journal of Geophysical Research Atmospheres, 2012, 95 (D10): 1634316367.

14. Stull R B. An Introduction to Boundary Layer Meteorology[J]. Atmospheric Sciences Library, 1988, 8(8):197245.

15. Stull R B, Driedonks A G. Applications of the transilient turbulence parameterization to atmospheric boundary layer simulations[J]. Boundary Layer Meteorology, 1987(40): 209-239.

(C) 2020 by the authors. Submitted for possible open access publication under the terms and conditions of the Creative Commons Attribution (CC BY) license (http://creativecommons.org/licenses/by/4.0/). 